\section{Commentary: Thoracic epidural anesthesia for pediatric cardiac surgery and enhanced recovery: Still lessons yet to be learned}

\author{
Barry D. Kussman, MBBCh, FFA(SA)
}

Neuraxial anesthesia may be used as an effective perioperative opioid-sparing modality for enhanced recovery in pediatric cardiac surgery. ${ }^{1}$ Correct anatomical placement of an epidural catheter is obligatory and advanced techniques, including fluoroscopy and ultrasonography, have been developed to facilitate or confirm accurate catheter placement. $^{2,3}$ In this issue of the Journal, Schmehil and colleagues ${ }^{4}$ report their experience with fluoroscopy-guided thoracic epidural catheter placement in a cohort of 120 patients (median age 24 months [range, 3 days-27 years] and weight $11 \mathrm{~kg}$ [range, 2.1-113 kg]) undergoing congenital heart surgery. The intention of this retrospective study was to evaluate the potential benefits of fluoroscopyguided thoracic epidural catheter placement as part of an enhanced recovery protocol. The primary outcome was successful fluoroscopy-guided thoracic epidural catheter placement, which was achieved in 119 patients (99\%). Although there were no complications and limited outcomes are presented, important limitations of the report are the absence of a control group and the lack of data (e.g., pain scores, opioid consumption, etc.) demonstrating the success of the epidural in providing the intended analgesia.

This brief report calls to attention 2 important factors to consider before choosing epidural anesthesia for congenital heart surgery. The first is the risk of paraplegia from epidural bleeding. In adult cardiac surgery, the risk of a

\footnotetext{
From the Department of Anesthesiology, Critical Care and Pain Medicine, Boston Children's Hospital; and Harvard Medical School, Boston, Mass.

Disclosures: The author reported no conflicts of interest.

The Journal policy requires editors and reviewers to disclose conflicts of interest and to decline handling or reviewing manuscripts for which they may have a conflict of interest. The editors and reviewers of this article have no conflicts of interest.

Received for publication Oct 13, 2021; revisions received Oct 13, 2021; accepted for publication Oct 22, 2021; available ahead of print Oct 28, 2021.

Address for reprints: Barry D. Kussman, MBBCh, FFA(SA), Department of Anesthesiology, Critical Care and Pain Medicine, Boston Children's Hospital, 300 Longwood Ave, Boston, MA 02115 (E-mail: barry.kussman@childrens.harvard.edu). JTCVS Techniques 2022;11:69-70

2666-2507

Copyright (C) 2021 The Author(s). Published by Elsevier Inc. on behalf of The American Association for Thoracic Surgery. This is an open access article under the CC BY-NC-ND license (http://creativecommons.org/licenses/by-nc-nd/4.0/).

https://doi.org/10.1016/j.xjtc.2021.10.048
}

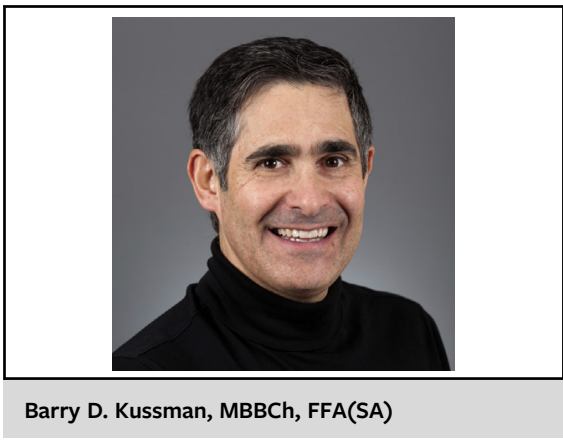

CENTRAL MESSAGE

Fluoroscopy-guided placement

of a thoracic epidural catheter

for pediatric heart surgery has a

high success rate, but any benefit

is constrained by the risk of

epidural hematoma and

paraplegia.

catheter-related epidural hematoma is about 1 in 5493 (95\% confidence interval, 1/970-1/3114). ${ }^{5}$ In pediatric cardiac surgery with placement of an epidural catheter about 60 minutes before heparinization, the $95 \%$ confidence limit for the maximal risk of spinal cord injury is about $2 \%$. With this high risk and the lack of comparative studies showing an extraordinary benefit of thoracic epidural analgesia over systemic intravenous analgesia and other regional anesthetic techniques, the choice of thoracic epidural anesthesia in pediatric cardiac surgery with anticoagulation is perhaps unwise. With placement of the catheter at the end of surgery, when hemostasis is restored clinically and can be verified by coagulation testing, plus the ability to perform a neurologic examination shortly thereafter, it is possible that the risk of epidural hematoma and paraplegia may be reduced. However, factors such as the need for postoperative anticoagulation, the timing of catheter removal, and the risk of bleeding associated with congenital heart disease need to be considered. ${ }^{7,8}$

The second factor is the relatively recent development of ultrasound-guided peripheral nerve blocks, which can be opioid-sparing. ${ }^{1}$ Bilateral erector spinae plane block has been shown in adult cardiac surgery to be a suitable alternative to thoracic epidural anesthesia for pain management and fast tracking ${ }^{9}$ and also to be opioid-sparing when compared with systemic analgesia. ${ }^{10}$ In a small cohort $(n=10)$ of 
children undergoing cardiac surgery with bypass and matched to historical controls, pain scores were low in both groups, and although postoperative opioid use at 48 hours was statistically less in the block group, this was clinically insignificant. ${ }^{11}$ Bilateral transverse thoracic muscle plane block with or without rectus sheath block is an alternative opioid-sparing regional block. ${ }^{12,13}$ Larger prospective comparative studies are required to demonstrate the safety and effectiveness of regional techniques and their contribution to enhanced recovery in pediatric cardiac surgery. ${ }^{1}$

\section{References}

1. Fuller S, Kumar SR, Roy N, Mahle WT, Romano JC, Nelson JS, et al. The American Association for Thoracic Surgery Congenital Cardiac Surgery Working Group 2021 consensus document on a comprehensive perioperative approach to enhanced recovery after pediatric cardiac surgery. J Thorac Cardiovasc Surg. 2021;162:931-54.

2. Guay J, Suresh S, Kopp S. The use of ultrasound guidance for perioperative neuraxial and peripheral nerve blocks in children. Cochrane Database Syst Rev. 2019;2:CD011436.

3. Lam H, Nguyen TT, Austin TM. Routine epidurography for epidural placement in anesthetized pediatric patients. Paediatr Anaesth. 2016;26:326-7.

4. Schmehil C, Lee K-J, Casella S, Millan D. Thoracic epidural anesthesia in congenital heart surgery. J Thorac Cardiovasc Surg Tech. 2022;11:64-6.

5. Hemmerling TM, Cyr S, Terrasini N. Epidural catheterization in cardiac surgery: the 2012 risk assessment. Ann Card Anaesth. 2013;16:169-77.
6. Peterson KL, DeCampli WM, Pike NA, Robbins RC, Reitz BA. A report of two hundred twenty cases of regional anesthesia in pediatric cardiac surgery. Anesth Analg. 2000;90:1014-9.

7. Horlocker TT, Vandermeuelen E, Kopp SL, Gogarten W, Leffert LR, Benzon HT. Regional anesthesia in the patient receiving antithrombotic or thrombolytic therapy: American Society of Regional Anesthesia and Pain Medicine evidence-based guidelines (fourth edition). Reg Anesth Pain Med. 2018;43:263-309.

8. Steven JM, McGowan FX Jr. Neuraxial blockade for pediatric cardiac surgery: lessons yet to be learned. Anesth Analg. 2000;90:1011-3.

9. Nagaraja PS, Ragavendran S, Singh NG, Asai O, Bhavya G, Manjunath N, et al. Comparison of continuous thoracic epidural analgesia with bilateral erector spinae plane block for perioperative pain management in cardiac surgery. Ann Card Anaesth. 2018;21:323-7.

10. Macaire P, Ho N, Nguyen T, Nguyen B, Vu V, Quach C, et al. Ultrasoundguided continuous thoracic erector spinae plane block within an enhanced recovery program is associated with decreased opioid consumption and improved patient postoperative rehabilitation after open cardiac surgery-a patientmatched, controlled before-and-after study. J Cardiothorac Vasc Anesth. 2019;33:1659-67.

11. Roy N, Brown ML, Parra MF, Sleeper LA, Alrayashi W, Nasr VG, et al. Bilateral erector spinae blocks decrease perioperative opioid use after pediatric cardiac surgery. J Cardiothorac Vasc Anesth. 2021;35:2082-7.

12. Yamamoto T, Seino Y, Matsuda K, Imai H, Bamba K, Sugimoto A, et al. Preoperative implementation of transverse thoracic muscle plane block and rectus sheath block combination for pediatric cardiac surgery. J Cardiothorac Vasc Anesth. 2020;34:3367-72.

13. Zhang Y, Chen S, Gong H, Zhan B. Efficacy of bilateral transversus thoracis muscle plane block in pediatric patients undergoing open cardiac surgery. $J$ Cardiothorac Vasc Anesth. 2020;34:2430-4. 